\section{CONCEPÇÕES DE EDUCAÇÃO AMBIEN- TAL E INTERDISCIPLINARIDADE DOS DOCENTES DO COLÉGIO ESTADUAL BE- NEDITO BARRETO DO NASCIMENTO}

\author{
Pedro Ernesto Oliveira da Cruz \\ Rodrigo Bozi Ferrete
}

\section{CONCEPTIONS OF ENVIRONMENTAL EDUCATION AND INTERDISCIPLINA- RITY OF TEACHERS OF THE STATE COLLEGE BENEDITO BARRETO DO NASCIMENTO}

\begin{abstract}
The present research came from the need to be analysed the different conceptions of teachers on this theme, seeking to understand how they insert environmental education in their pedagogical practices, in their areas of knowledge and how the process of integration with other disciplines occurs. Through a descriptive case study, a questionnaire applied to ten professors of the Benedito Barreto do Nascimento State College was used as instrument. The collected responses were submitted to content analysis by Bardin (2011). The results showed that the teachers' conceptions about environmental education are quite heterogeneous, revealing that the daily experiences of each one, together with the formation of their area, influence the way they conceive the world and understand environmental problems. Regarding interdisciplinarity, we realize that most teachers understand some aspects of interdisciplinarity, however they have not yet built a solid concept on the subject, thus revealing some flaw in their higher education and also in the continuity of their formation.
\end{abstract}

Keywords: Environmental Education, Interdisciplinarity, Teacher conceptions.

Palavras-chave: Educação ambiental, interdisciplinaridade, concepções de professores. 


\section{Introdução}

Vivemos hoje em um planeta cheio de problemas ambientais sérios, como o aumento da temperatura global, desmatamento de áreas verdes, crescente poluição, desaparecimento de várias espécies de seres vivos, aumento exagerado do lixo, entre outros. Muitos desses problemas são frutos do desequilíbrio da relação homem/natureza.

Neste cenário, surge a necessidade emergencial de uma maior preocupação sobre as nossas ações para o meio ambiente, através de modelos educacionais que possibilitem compreender a dimensão do problema e dos vários fatores envolvidos, além de uma reformulação dos valores da sociedade.

Os Parâmetros Curriculares Nacionais propõem o Tema Transversal Meio Ambiente em função de sua emergência, abordando a educação como elemento indispensável para a transformação da consciência ambiental. No mesmo documento há menção da necessidade de superação da fragmentação do saber nas situações de ensino e da transversalidade do tema Meio Ambiente nas áreas bem como a relação entre a comunidade e a escola (BRASIL, 1998).

A educação ambiental torna-se assim um importante recurso no trabalho de sensibilização do homem junto ao meio ambiente. No entanto, a concepção de educação ambiental ainda não está consolidada, e muitos pesquisadores concordam que ainda é um conceito em construção. Assim, vários autores como Reigota (1995), Marcos Sorrentino (1995) e Suavé (2005), tentaram categorizar as diferentes concepções de educação ambiental.

Surge, então, uma diversidade de concepções e propostas contraditórias sobre a educação ambiental, principalmente devido ao seu caráter interdisciplinar, onde os sujeitos (pesquisadores, professores, associações, entre outros) das mais diferentes áreas, com visões diferentes de mundo, defendem ideias diferentes.

Japiassú (1976, p. 74) nos diz que, "a interdisciplinaridade caracteriza-se pela intensidade das trocas entre os especialistas e pelo grau de interação real das disciplinas no interior de um mesmo projeto de pesquisa". Dessa forma, a união das diferentes disciplinas para a discussão de uma mesma temática leva a uma reflexão mais profunda sobre o tema.

Os Parâmetros Curriculares Nacionais do Ensino Médio (PCNs) orientam para o desenvolvimento de um currículo que contemple a interdisciplinaridade:

A interdisciplinaridade não dilui as disciplinas, ao contrário, mantém sua individualidade. Mas integra as disciplinas a partir da compreensão das múltiplas causas ou fatores que intervêm sobre a realidade e trabalha todas as linguagens necessárias para a constituição de conhecimentos, comunicação e negociação de significados e registro sistemático dos resultados. (BRASIL, 1999, p. 89)

Com esta orientação, os PCNs explicitam que um projeto interdisciplinar mantém o caráter individual de cada disciplina ao passo que a integração entre elas permite com que cada área dê a sua contribuição, levando os alunos a sistematizá-las e a construir os seus conceitos.

Assim, a prática de educação ambiental na abordagem interdisciplinar é uma escolha política a ser tomada pelos educadores:

\section{(...) a educação ambiental deve ser uma concepção totalizadora de educação e que é possível quando resulta de um pro- jeto político pedagógico orgânico, cons- truído coletivamente na interação escola e comunidade, e articulado com os mo- vimentos populares organizados com- prometidos com a preservação da vida em seu sentido mais profundo (GARCIA apud GUIMARÃES, 2000, p. 68).}

É política por que considera a escola como um espaço de formação de cidadãos críticos, conscientes e atuantes na sociedade de forma individual e coletiva. Um dos critérios para a realização de uma educação ambiental efetiva.

Nesse contexto, entendemos que o professor das diferentes áreas possui um papel importante para o estabelecimento da educação ambiental.

A presente pesquisa surgiu da necessidade de analisarmos as diferentes concepções dos professores sobre esta temática, buscando compreender como eles inserem a educação ambiental nas suas 
práticas pedagógicas, em suas áreas de conhecimento e como se dá o processo de integração com outras disciplinas.

Assim, o objetivo deste trabalho foi analisar as concepções de educação ambiental e interdisciplinaridade de professores de uma escola pública do município de Umbaúba, Sergipe.

$\mathrm{Na}$ literatura, alguns autores já abordaram sobre esta temática. Souza (2012), buscou mapear as concepções de educação ambiental e de interdisciplinaridade adotadas pelos professores e gestores das escolas públicas estaduais, localizadas na cidade de Abreu e Lima, no estado de Pernambuco, objetivando compreendê-las para identificar as principais dificuldades desse fazer pedagógico.

Pesquisa realizada por Castôr (et al., 2014), analisou as concepções de educação ambiental de um grupo de professores de uma escola pública de Ensino Médio de Cariacica, ES.

Zamoner (et al., 2004) analisaram referenciais de conhecimento de professores atuantes na Educação Básica do município de Colombo no que diz respeito a seu entendimento e prática da educação ambiental pela abordagem interdisciplinar

Esses trabalhos possuem em comum com esta pesquisa a análise das concepções dos professores sobre educação ambiental e interdisciplinaridade e difere quanto ao aspecto local, uma vez que os sujeitos a serem pesquisados fazem dela uma pesquisa inédita.

A pesquisa mostra-se relevante na medida em que procura identificar como professores de diferentes áreas veem e praticam a educação ambiental e como a relaciona com as demais áreas do conhecimento. Tal estudo pode servir como referências posteriores para a construção de atividades interdisciplinares voltadas para a educação ambiental.

\section{Metodologia}

A presente pesquisa foi realizada com os docentes do Colégio Estadual Benedito Barreto do Nascimento, situado na cidade de Umbaúba/SE, que atualmente oferece o Ensino Fundamental Maior, o Ensino Médio e a Educação de Jovens e Adultos na modalidade Ensino Médio. A escolha por esta Unidade de Ensino está no fato do pesquisador ser professor atuante na mesma e ter percebido que a educação ambiental é pouco implementada na referida escola.

Para a pesquisa, foi utilizado como abordagem metodológica, o estudo de caso descritivo. Conforme Patton (2002), o estudo de caso tem como propósito reunir informações detalhadas e sistemáticas sobre um fenômeno. Já a abordagem descritiva "tem como objetivo conhecer as diversas situações e relações que ocorrem a vida social política, econômica e os demais aspectos do comportamento humano" (CERVO et al, 2007, p. 62). Dessa forma, a abordagem descritiva nos permitiu identificar a relação dos professores investigados com o seu meio social.

O enfoque da pesquisa foi o qualitativo, uma vez que os fenômenos foram analisados na sua complexidade e singularidade. $\mathrm{Na}$ abordagem qualitativa, pesquisador e pesquisado estabelecem uma relação de interdependência. Segundo Chizzotti (1991, p. 79),

o conhecimento não se reduz a um rol de dados isolados, conectados por uma teoria explicativa; o sujeito observador é parte integrante do processo de conhecimento e interpreta os fenômenos, atribuindo-lhes um significado. $\mathrm{O}$ objeto não é um dado inerte e neutro; está possuído de significados e relações que sujeitos concretos criam em suas ações.

Assim, podemos analisar o significado das respostas, levando em consideração o meio em que estamos inseridos.

O instrumento de coleta de dados utilizado foi um questionário. A escolha por este instrumento deu-se em virtude do número de pessoas que permite alcançar em um intervalo curto de tempo, além de favorecer a tabulação das respostas. Questionários são instrumentos que servem de apoio aos pesquisadores para os processos de coleta de dados e apresentam os seguintes aspectos: são a espinha dorsal de qualquer levantamento; precisam reunir todas as informações necessárias, nem mais nem menos; devem ter uma linguagem adequada, ou seja, uma certa dose de visão psicológica introspectiva para apanhar o pensamento das pessoas (OLIVEIRA, 1997).

O questionário foi aplicado a um professor por 
disciplina. No caso de disciplinas que possuíam mais de um professor, o critério de escolha foi o maior tempo de serviço na escola. O questionário foi distribuído a doze professores, no entanto dois não o devolveram, perfazendo então uma amostra total de dez professores. Com o questionário foi possível identificar como se dá as práticas de educação ambiental na referida Unidade de Ensino, permitindo-se ter uma visão global da formação educacional proporcionada aos seus alunos.

Os dados coletados foram submetidos a análise de conteúdo. Bardin (2011, p. 38) refere que a análise de conteúdo consiste em:

um conjunto de técnicas de análise das comunicações, que utiliza procedimentos sistemáticos e objetivos de descrição do conteúdo das mensagens. ... A intenção da análise de conteúdo é a inferência de conhecimentos relativos às condições de produção (ou eventualmente, de recepção), inferência esta que recorre a indicadores (quantitativos ou não).

Nesta técnica o pesquisador busca compreender os significados que estão por trás das mensagens sendo, portanto, uma metodologia satisfatória para esta pesquisa.

A análise de conteúdo nos permitiu analisar as respostas dos professores seguindo as três etapas propostas por Bardin (2011): pré-análise, exploração do material e tratamento dos resultados.

Em relação a concepção de educação ambiental, foram feitas quatro perguntas:

1) Em sua opinião, o que é educação ambiental?

2) Em sua opinião, qual a origem (ou origens) dos problemas ambientais?

3) Quais seriam as soluções para os problemas ambientais?

4) Em que matéria você acha que a educação ambiental deve ser ensinada?

As respostas obtidas foram agrupadas em categorias, utilizando como referência as concepções de educação ambiental identificadas por Suavé (2005), modificadas por Nero e Frenedozo (2009), que reduziram as quinze categorias de Suavé (2005) em sete, devido as suas semelhan- ças, a saber:

Quadro 1: concepções de educação ambiental adaptadas por Nero e Frenedozo (2009) a partir de Sauvé (2005).

\begin{tabular}{|c|c|}
\hline Concepção & Abordagem educativa \\
\hline $\begin{array}{l}\text { Naturalista } \\
\text { Bio- regio- } \\
\text { nalista } \\
\text { Etnográfica }\end{array}$ & $\begin{array}{l}\text { A EA é conseguida na natureza, } \\
\text { a qual é valorizada como meio } \\
\text { de aprendizagem e não como } \\
\text { fonte de recursos, devendo o } \\
\text { homem retornar à terra, às suas } \\
\text { raízes regionais, valorizando o } \\
\text { compartilhamento com o meio } \\
\text { ambiente e levando em conta a } \\
\text { cultura de referência das popula- } \\
\text { ções e das comunidades. }\end{array}$ \\
\hline $\begin{array}{l}\text { Conserva- } \\
\text { cionista } \\
\text { Resolutiva }\end{array}$ & $\begin{array}{l}\text { A EA visa identificar os proble- } \\
\text { mas ambientais e propor solu- } \\
\text { ções para a conservação dos re- } \\
\text { cursos naturais, principalmente } \\
\text { dos recursos necessários à ma- } \\
\text { nutenção das necessidades da } \\
\text { sociedade. }\end{array}$ \\
\hline Sistêmica & $\begin{array}{l}\text { A EA visa identificar os proble- } \\
\text { mas ambientais no conhecimen- } \\
\text { to da(s) causa(s) que o origina- } \\
\text { ram e seus efeitos, através do } \\
\text { estudo de observação e experi- } \\
\text { mentação. }\end{array}$ \\
\hline $\begin{array}{c}\text { Humanista } \\
\text { Holística } \\
\text { Feminista }\end{array}$ & $\begin{array}{l}\text { A EA deve valorizar a expres- } \\
\text { são do meio ambiente de forma } \\
\text { cultural, considerando a indi- } \\
\text { vidualidade de cada ser que irá } \\
\text { trabalhar de maneira criativa } \\
\text { (criatividade técnica, artesanal, } \\
\text { artística, construtiva) em cola- } \\
\text { boração com as forças da nature- } \\
\text { za, diminuindo assim as relações } \\
\text { de poder e discriminação dentro } \\
\text { dos grupos sociais. }\end{array}$ \\
\hline $\begin{array}{c}\text { Moral/ética } \\
\text { Crítica-So- } \\
\text { cial }\end{array}$ & $\begin{array}{l}\text { A EA deve desencadear princí- } \\
\text { pios éticos ambientais, que são } \\
\text { individuais e construídos a partir } \\
\text { de situações de conflito moral e } \\
\text { de análise das dinâmicas sociais } \\
\text { que estão na base das realidades } \\
\text { e problemáticas ambientais. }\end{array}$ \\
\hline
\end{tabular}




\begin{tabular}{|c|l|}
\hline \multirow{2}{*}{ Prática } & $\begin{array}{l}\text { A EA deve incentivar a ação } \\
\text { como meio de aprendizado atra- } \\
\text { vés da reflexão dos resultados } \\
\text { obtidos perante uma problemáti- } \\
\text { ca ambiental. }\end{array}$ \\
\hline Eco-educa- \\
ção & $\begin{array}{l}\text { A EA deve aproveitar da rela- } \\
\text { ção com o meio ambiente como } \\
\text { mecanismo de desenvolvimento } \\
\text { pessoal, de forma a criar no in- } \\
\text { divíduo uma atuação crítica e } \\
\text { responsável, desencadeando no } \\
\text { mesmo uma nova concepção de } \\
\text { sustentabilentabilidade } \\
\text { dade }\end{array}$ \\
\hline
\end{tabular}

Fonte: Nero e Frenedozo (2009).

O questionário possuía ainda perguntas relativas a concepção de interdisciplinaridade:

1) Em sua opinião, o que é interdisciplinaridade?

2) Em sua opinião, existe alguma relação entre educação ambiental e interdisciplinaridade?

As respostas foram agrupadas em categorias de acordo com semelhanças em seu conteúdo e analisadas à luz dos teóricos pertinentes a investigação.

\section{Resultados e discussão}

Quanto ao perfil dos professores que responderam o questionário, $80 \%$ são do sexo masculino, mostrando ser uma escola atípica, pois de acordo com dados da Sinopse do Professor da Educação Básica divulgada pelo MEC (Ministério da Educação), no fim de 2010, 81,5\% dos professores de educação básica eram do sexo feminino, desmistificando assim a associação da função de professor a características geralmente consideradas femininas, como a delicadeza, a meiguice e a atenção.

Em relação à idade, $10 \%$ dos professores entrevistados possuem até 25 anos, $50 \%$ possuem entre 26 e 30 anos, $10 \%$ entre 31 e 40 anos e $30 \%$ entre 41 e 50 anos. São, portanto, em sua maioria, professores jovens e recém-formados.

Sobre o tempo de exercício no magistério, $50 \%$ dos professores exercem entre 5 e 10 anos, 20\% entre 1 e 3 anos e $30 \%$ a mais de 20 anos. $O$ tempo de exercício é importante na definição da proposta pedagógica de cada professor, pois está relacionado com o fator experiência e consequentemente com a habilidade de se relacionar com os demais colegas de trabalho para a execução de práticas interdisciplinares.

A formação profissional dos entrevistados foi: $60 \%$ possuem ensino superior completo, $10 \%$ possuem especialização, $20 \%$ possuem mestrado incompleto e $10 \%$ já concluíram o mestrado.

Em relação a realização de cursos de capacitação/ atualização profissional nos últimos 2 anos, 30\% dos professores disseram terem realizado apenas um, 20\% disseram que realizaram dois, $20 \%$ realizaram mais de três e $30 \%$ não realizou nenhum. A realização de cursos de capacitação/atualização profissional é muito importante para a prática pedagógica, pois estamos diariamente diante de novas problemáticas da sociedade.

O perfil dos professores entrevistados pode ser definido então como, professores jovens, em constante formação e com experiência em sala de aula. Trata-se de um perfil promissor para enfrentar os problemas da educação brasileira.

Em relação as concepções de educação ambiental, obtivemos as seguintes respostas:

Quadro 2: Concepções de educação ambiental dos professores investigados

\begin{tabular}{|l|l|l|}
\hline Disciplina & $\begin{array}{l}\text { Concepção } \\
\text { de educa- } \\
\text { ção am- } \\
\text { biental }\end{array}$ & \multicolumn{1}{c|}{ Respostas do professor } \\
\hline \multirow{2}{*}{ Espanhol } & $\begin{array}{l}\text { 1-“É a área do conhecimen- } \\
\text { to que instrui o indivíduo a } \\
\text { conhecer a importância do } \\
\text { meio ambiente e sua conser- } \\
\text { vação". } \\
\text { cionista } \\
\text { Humanista } \\
\text { 2- "O próprio ser humano } \\
\text { que não tem conhecimento } \\
\text { da importância deste". } \\
\text { 3- "Mudar a consciência do } \\
\text { ser humano, mostrando as- } \\
\text { sim, como o papel de ser } \\
\text { conservador pode contribuir } \\
\text { para a solução dos problemas } \\
\text { ambientais". } \\
\text { 4- "Ciências, biologia, geo- } \\
\text { grafia, história, sociedade e } \\
\text { cultura". }\end{array}$ \\
\hline
\end{tabular}




\begin{tabular}{|c|c|c|}
\hline $\begin{array}{c}\text { Matemá- } \\
\text { tica }\end{array}$ & $\begin{array}{l}\text { Naturalista } \\
\text { Conserva- } \\
\text { cionista } \\
\text { Sistêmica } \\
\text { Humanista } \\
\text { Moral/ética }\end{array}$ & $\begin{array}{l}\text { 1- "Entender que a preserva- } \\
\text { ção do meio ambiente é es- } \\
\text { sencial para a vida no planeta } \\
\text { terra. Desta forma, respeitar } \\
\text { e preservar a biodiversida- } \\
\text { de". } \\
\text { 2- "O uso irracional da ciên- } \\
\text { cia e da tecnologia, criado } \\
\text { pelo homem para garantir a } \\
\text { sua sobrevivência às condi- } \\
\text { ções do meio". } \\
\text { 3- "Formar pessoas cons- } \\
\text { cientes ambientalmente, para } \\
\text { que ocorra mudança na base } \\
\text { da sociedade, originando } \\
\text { pessoas preocupadas com os } \\
\text { problemas ambientais". } \\
\text { 4- "Todas as disciplinas". }\end{array}$ \\
\hline Artes & $\begin{array}{l}\text { Naturalista } \\
\text { Conserva- } \\
\text { cionista } \\
\text { Eco-educa- } \\
\text { ção } \\
\text { Prática }\end{array}$ & $\begin{array}{l}\text { 1- "Toda ação educativa que } \\
\text { contribui para a formação de } \\
\text { indivíduos quanto a preser- } \\
\text { vação do meio ambiente e } \\
\text { aptos a tomar decisões cole- } \\
\text { tivas quanto aos problemas } \\
\text { ambientais, a fim de propor- } \\
\text { cionar soluções para um de- } \\
\text { senvolvimento sustentável". } \\
\text { 2- "De natureza humana } \\
\text { principalmente pela má utili- } \\
\text { zação dos recursos naturais". } \\
\text { 3- "Promover através de } \\
\text { "educação contínua e perma- } \\
\text { nente' ações conscientes que } \\
\text { primam pelo desenvolvimen- } \\
\text { to sustentável. Formação de } \\
\text { educadores sustentáveis". } \\
\text { 4- "Todas, pois a EA é de in- } \\
\text { teresse universal". }\end{array}$ \\
\hline Português & $\begin{array}{l}\text { Naturalista } \\
\text { Conserva- } \\
\text { cionista } \\
\text { Eco-educa- } \\
\text { ção } \\
\text { Moral/ética }\end{array}$ & $\begin{array}{l}\text { 1- "A educação ambiental é } \\
\text { um conjunto de saberes que } \\
\text { possibilita o desenvolvimen- } \\
\text { to humano pautado no de- } \\
\text { senvolvimento sustentável e } \\
\text { o uso racional dos recursos } \\
\text { naturais". } \\
\text { 2- "A desvinculação entre } \\
\text { homem e natureza acelerada } \\
\text { após a revolução industrial". } \\
\text { 3- "Todos os seres humanos } \\
\text { se responsabilizarem pela } \\
\text { preservação dos ecossiste- } \\
\text { mas e a defesa da vida no } \\
\text { planeta". } \\
\text { 4- "Em todas, de maneira in- } \\
\text { terdisciplinar". }\end{array}$ \\
\hline
\end{tabular}

\begin{tabular}{|c|c|c|}
\hline Inglês & $\begin{array}{l}\text { Humanista } \\
\text { Sistêmica } \\
\text { Prática }\end{array}$ & $\begin{array}{l}\text { 1- "Estudo que abrange não } \\
\text { apenas conteúdos relacio- } \\
\text { nados com o meio ambien- } \\
\text { te, mas essencialmente com } \\
\text { proposta de mudança de } \\
\text { comportamento em relação } \\
\text { ao planeta e comportamento } \\
\text { interativo". } \\
\text { 2- "Ignorância e ambição, } \\
\text { sem controle fiscal". } \\
\text { 3- "Esclarecimento em todas } \\
\text { as escalas sociais". } \\
\text { 4- "Todas - transdisciplinari- } \\
\text { dade com projetos de traba- } \\
\text { lho". }\end{array}$ \\
\hline Biologia & $\begin{array}{l}\text { Naturalista } \\
\text { Conserva- } \\
\text { cionista } \\
\text { Moral/ética }\end{array}$ & $\begin{array}{l}\text { 1- "É uma educação volta- } \\
\text { da para a conscientização } \\
\text { da importância do ambiente } \\
\text { para a nossa sobrevivência". } \\
\text { 2- "A falta de consciência } \\
\text { das pessoas". } \\
\text { 3- "Consciência das pessoas } \\
\text { e respeito com o ambiente". } \\
\text { 4- "Em todas as matérias". }\end{array}$ \\
\hline Física & $\begin{array}{l}\text { Naturalista } \\
\text { Conserva- } \\
\text { cionista }\end{array}$ & $\begin{array}{l}\text { 1- "Educação ambiental seria } \\
\text { a utilizaçáo de forma correta } \\
\text { das matérias-primas, assim } \\
\text { como o descarte correto dos } \\
\text { materiais não-utilizados". } \\
\text { 2- "A má utilização dos re- } \\
\text { cursos naturais pelo ser hu- } \\
\text { mano". } \\
\text { 3- "Conscientização dos } \\
\text { problemas ambientais desde } \\
\text { criança nas escolas". } \\
\text { 4- "Em todas as disciplinas". }\end{array}$ \\
\hline Geografia & $\begin{array}{l}\text { Naturalista } \\
\text { Conserva- } \\
\text { cionista } \\
\text { Eco-educa- } \\
\text { ção } \\
\text { Prática }\end{array}$ & $\begin{array}{l}\text { 1- "Trabalho de conscienti- } \\
\text { zação sobre a necessidade } \\
\text { de preservação ambiental e } \\
\text { desenvolvimento de práticas } \\
\text { relativas a essa temática". } \\
\text { 2- "O modelo econômico } \\
\text { vigente que estimula o con- } \\
\text { sumismo e uma industriali- } \\
\text { zação para abastecer o mes- } \\
\text { mo. Tudo isso de forma não } \\
\text { sustentável". } \\
\text { 3- "Desenvolvimento e exe- } \\
\text { cução de práticas sustentá- } \\
\text { veis por parte das grandes } \\
\text { empresas. Ações individuais } \\
\text { contribuem, mas não são de- } \\
\text { terminantes". } \\
\text { 4- "Em várias, as especial- } \\
\text { mente em geografia e biolo- } \\
\text { gia". }\end{array}$ \\
\hline
\end{tabular}




\begin{tabular}{|c|c|c|}
\hline Ciências & $\begin{array}{l}\text { Naturalista } \\
\text { Conserva- } \\
\text { cionista }\end{array}$ & $\begin{array}{l}\text { 1- "É uma forma de cons- } \\
\text { cientizar a respeito da impor- } \\
\text { tância do ambiente natural e } \\
\text { também do ambiente urbano } \\
\text { e sua preservação, evitando } \\
\text { poluiçãa, entre outras medi- } \\
\text { das". } \\
\text { 2- "A falta de conscientiza- } \\
\text { ção das pessoas, pois poluem } \\
\text { o ambiente como se fosse a } \\
\text { coisa mais normal e não se } \\
\text { importam com as consequên- } \\
\text { cias". } \\
\text { 3- "Uma maior conscientiza- } \\
\text { ção das pessoas, como tam- } \\
\text { bém uma melhor infraestru- } \\
\text { tura, com lixeiros em todas } \\
\text { as ruas, automóveis menos } \\
\text { poluidores, combustíveis re- } \\
\text { nováveis, entre outros". } \\
\text { 4- "Em biologia, ciências e } \\
\text { nas demais disciplinas tam- } \\
\text { bém deve ser abordada". }\end{array}$ \\
\hline $\begin{array}{l}\text { Educação } \\
\text { Física }\end{array}$ & $\begin{array}{l}\text { Naturalista } \\
\text { Conser- } \\
\text { vacionista } \\
\text { Moral/ética } \\
\text { Eco-educa- } \\
\text { ção }\end{array}$ & $\begin{array}{l}\text { 1- "Uma área que usa a for- } \\
\text { mação cidadã através dos } \\
\text { ensinamentos voltados para } \\
\text { a relação homem/natureza". } \\
\text { 2- "A intervenção do homem } \\
\text { na busca de interesses capi- } \\
\text { talistas". } \\
\text { 3- "Um trabalho de cons- } \\
\text { cientização mais elaborado". } \\
\text { 4- "Todas. Em minha visão } \\
\text { não existe uma divisão para } \\
\text { se trabalhar com EA no am- } \\
\text { biente escolar". }\end{array}$ \\
\hline
\end{tabular}

Fonte: Dados da pesquisa.

$\mathrm{O}$ quadro nos mostra que os professores de todas as disciplinas, exceto de inglês, possuem uma visão naturalista e conservacionista, quando atribuem grande valor aos processos educacionais que envolvem conservação, conscientização e preservação do meio ambiente.

A corrente naturalista é centrada na relação com a natureza. $\mathrm{O}$ enfoque educativo pode ser cognitivo (aprender com coisas sobre a natureza), experiencial (viver na natureza e aprender com ela), afetivo, espiritual ou artístico (associando a criatividade humana à da natureza) (SUAVÉ, 2005).

A corrente conservacionista/recursista agrupa as proposições centradas na "conservação" dos recursos, tanto no que concerne à sua qualidade quando à sua quantidade. É um programa centrado nos 3 "Rs" Redução, Reutilização e Recicla- gem, ou aqueles centrados na gestão da água e gestão do lixo por exemplo (SUAVÉ, 2005).

Estas concepções sempre estiveram presentes na nossa educação familiar ou comunitária por ter uma tradição mais antiga na educação ambiental. Possivelmente, essa tradição reflete na formação dos professores entrevistados e consequentemente influencia a sua forma de ver o mundo e de lecionar.

A concepção humanista pôde ser encontrada nas respostas dos professores de espanhol e matemática ao encontrarmos elementos como "mudar a consciência do ser humano" e "mudança na base da sociedade".

A corrente humanística dá ênfase à dimensão humana do meio ambiente, construído no cruzamento da natureza e da cultura. Nela, o ambiente corresponde a um meio de vida, com suas dimensões históricas, culturais, políticas, econômicas, estéticas, etc. (SUAVÉ, 2005).

Dessa forma, estes professores acreditam na importância da individualidade do aluno no envolvimento das questões ambientais, refletindo assim na sua vida e de toda a comunidade.

Nas respostas dos professores de matemática e inglês pode ser notada ainda a presença de elementos da concepção sistêmica ao mencionarem termos como "ciência e tecnologia" e "transdisciplinaridade".

O enfoque sistêmico permite conhecer e compreender adequadamente as realidades e as problemáticas ambientais, possibilitando identificar os diferentes componentes de um sistema ambiental e salientar as relações entre seus componentes, como as relações entre os elementos biofísicos e os sociais de uma situação ambiental. Também está associado ao desenvolvimento de conhecimentos e de habilidades relativas às ciências do meio ambiente, do campo de pesquisa essencialmente interdisciplinar para a transdisciplinaridade (SUAVÉ, 2005).

Observamos que os professores que concebem a educação ambiental com um enfoque sistêmico, veem a necessidade de identificar as causas dos problemas ambientais e seus efeitos numa perspectiva profunda e abrangente de caráter transdisciplinar. Curiosamente, esta concepção tem 
semelhanças com o método científico e é normalmente adotada por professores de ciências da natureza.

A concepção prática foi observada nas respostas dos professores de artes, português, inglês e geografia. Em suas respostas foram encontrados elementos como "ação e reflexão", "repensar atitudes" e "fiscalização". Segundo Suavé (2005), a corrente prática tem ênfase na aprendizagem na ação, pela ação e para a melhora desta. Deve incentivar a ação como meio de aprendizado através da reflexão dos resultados obtidos perante uma problemática ambiental. Portanto, os professores que possuem a concepção prática expressam uma necessidade de ação/reflexão para a resolução dos problemas ambientais.

Os professores de matemática, biologia e educação física apresentaram em suas respostas também a concepção moral/ética.

A corrente moral/ética considera que o fundamento da relação com o meio ambiente é de ordem ética, e é neste nível que se deve intervir de maneira prioritária, baseando em um conjunto de valores, mais ou menos conscientes e coerentes entre eles (SUAVÉ, 2005).

Nesse sentido, observamos nas respostas desses professores, uma preocupação com a formação de valores e princípios éticos e ambientais.

Por fim, encontramos a concepção de eco educação nas respostas dos professores de artes, português, inglês e geografia.

A eco educação está dominada pela perspectiva educacional da educação ambiental. Não se trata de resolver problemas, mas de aproveitar a relação com o meio ambiente para o desenvolvimento pessoal, para o fundamento de um atuar significativo e responsável. Concebe o ambiente como recursos para o desenvolvimento econômico, recursos compartilhados. Seus objetivos referem-se a promover um desenvolvimento econômico respeitoso dos aspectos sociais e do meio ambiente e contribuir para esse desenvolvimento (SUAVÉ, 2005).

Os professores de artes, português, inglês e geografia, defendem dentro da concepção da eco educação, uma preocupação pela formação de alunos com uma consciência crítica, que critique o modelo econômico capitalista e esteja dentro dos moldes da sustentabilidade

Todas essas respostas mostram a heterogeneidade nas concepções da educação ambiental, devido à complexidade que se é concebido o ambiente e "deve ser vista como uma proposta teórica e será vantajoso que constitua objeto de discussões críticas" (SUAVÉ, 2005, p. 18), possibilitando um aprofundamento nos conhecimentos teóricos e metodológicos para o educador ambiental

Dessa maneira, a educação ambiental está ultrapassando a ideia tradicional de que só deve ser contemplada pelas disciplinas de ciências da natureza (química, física, biologia e ciências), sendo, portanto, vista de maneira positiva pelos professores das mais diferentes áreas do conhecimento.

Vale ressaltar que entre os dez professores pesquisados, três estão concluindo uma especialização na área de educação ambiental (professores de português, artes e educação física). Isso mostra que existe um interesse pela educação ambiental independente da sua formação ou área de atuação, aprimorando, como consequência, a sua prática pedagógica.

Ficou constatado ainda que $70 \%$ dos professores relataram que em seu curso de graduação não existiam disciplinas voltadas para a educação ambiental. Os 30\% restante correspondem aos professores da área de geografia, biologia e ciências. Dessa forma, observamos que a educação ambiental ainda é pouco retratada nas universidades, exceto nos cursos que estão diretamente relacionados com o meio ambiente. A ausência de uma formação básica sobre a educação ambiental afeta a prática pedagógica do professor, uma vez que os professores utilizam como referência majoritária o seu curso de graduação.

Quando perguntados se já realizaram algum trabalho de educação ambiental com seus alunos, $70 \%$ disseram que sim. Disseram que não, os professores de ciências, física e matemática.

Percebemos que, independente da concepção de educação ambiental, a mesma já é uma realidade na escola objeto de estudo, atendendo a necessidade de se discutir esta temática em sala de aula. Nos surpreende a resposta negativa do professor 
de ciências, pois a educação ambiental é uma temática que faz parte da ementa da disciplina.

Od quadro 02 nos mostrou ainda que 9 dos 10 professores (excetuando o professor de espanhol) consideram que a educação ambiental deve ser trabalhada em todas as disciplinas e tem, portanto, um caráter interdisciplinar.

Em relação as concepções de interdisciplinaridade dos professores, obtivemos as seguintes respostas:

Quadro 3: Concepções de interdisciplinaridade dos professores investigados

\begin{tabular}{|c|c|}
\hline Categorias & Respostas do professor \\
\hline $\begin{array}{l}\text { Envolver } \\
\text { várias dis- } \\
\text { ciplinas ou } \\
\text { áreas }\end{array}$ & $\begin{array}{l}\text { Geografia } \\
\text { 1- "A integração das disciplinas. A reali- } \\
\text { zação de trabalhos em conjunto com pro- } \\
\text { fessores de disciplinas e áreas diferentes" } \\
\text { 2- "Sim. É uma área que abre grandes pos- } \\
\text { sibilidades de trabalho em conjunto". }\end{array}$ \\
\hline $\begin{array}{l}\text { Tema ou } \\
\text { assunto a } \\
\text { ser estuda- } \\
\text { do, papel } \\
\text { central, } \\
\text { como uni- } \\
\text { ficador das } \\
\text { disciplinas }\end{array}$ & $\begin{array}{l}\text { Biologia } \\
\text { 1- "É o trabalho conjunto de um determi- } \\
\text { nado assunto". } \\
\text { 2- "Sim. A educação ambiental é questão } \\
\text { a ser trabalhada por todas as disciplinas, } \\
\text { dessa maneira é interdisciplinar". } \\
\text { Espanhol } \\
\text { 1- "É quando um tema de uma determina- } \\
\text { da matéria é abordado em outra disciplina } \\
\text { com fins de interação deste tema entre es- } \\
\text { tas matérias". } \\
\text { 2- "Sim. Pois a educação ambiental pode, } \\
\text { e deve ser abrangida em qualquer área do } \\
\text { conhecimento". }\end{array}$ \\
\hline $\begin{array}{l}\text { Devem ter } \\
\text { pontos em } \\
\text { comum ou } \\
\text { um objetivo } \\
\text { comum. }\end{array}$ & $\begin{array}{l}\text { Matemática } \\
\text { 1- "Processo de integração recíproca entre } \\
\text { várias disciplinas e campos de conheci- } \\
\text { mento. Associação de disciplinas por um } \\
\text { objeto comum". } \\
\text { 2- "Sim, pois educação ambiental é um ob- } \\
\text { jeto comum a várias disciplinas". } \\
\text { Artes } \\
\text { 1- "Tornar outros ramos de conhecimentos } \\
\text { comum a duas ou mais disciplinas". } \\
\text { 2- "Sim. Através da interdisciplinaridade é } \\
\text { possível difundir ainda mais os conceitos } \\
\text { em EA proporcionando interatividade a } \\
\text { partir dos conhecimentos afins". }\end{array}$ \\
\hline
\end{tabular}

\begin{tabular}{|c|c|}
\hline $\begin{array}{l}\text { Planeja- } \\
\text { mento das } \\
\text { práticas pe- } \\
\text { dagógicas }\end{array}$ & $\begin{array}{l}\text { Português } \\
\text { 1- "A junção de saberes de áreas distintas } \\
\text { com a finalidade de promover o cresci- } \\
\text { mento das práticas pedagógicas". } \\
\text { 2- "Sim, acredito que o melhor caminho } \\
\text { para se introduzir a educação ambiental na } \\
\text { escola deva ser por meio de um trabalho } \\
\text { interdisciplinar". } \\
\text { Educação Física } \\
\text { 1- "É o desenvolvimento de um ensino } \\
\text { planejado que contempla uma interação } \\
\text { entre o conhecimento, promovendo um } \\
\text { enriquecimento de valores e saberes". } \\
\text { 2- Sim. A interação dos conhecimentos ob- } \\
\text { tidos a partir da interdisciplinaridade, faz } \\
\text { jus a proposta da educação ambienta". } \\
\text { Inglês } \\
\text { 1- "Diálogo - solidariedade didática". } \\
\text { 2- "Se não existir, deve haver!". }\end{array}$ \\
\hline $\begin{array}{l}\text { Contato } \\
\text { superficial } \\
\text { e informal } \\
\text { entre as } \\
\text { disciplinas }\end{array}$ & $\begin{array}{l}\text { Física } \\
\text { 1- "É a visão ampla de um determinado } \\
\text { conceito, abordado de diversas formas e } \\
\text { visões diferentes" } \\
\text { 2- "Sim". } \\
\text { Ciências } \\
\text { 1- "É utilizar conhecimentos de outras } \\
\text { áreas que possam ajudar na aprendizagem } \\
\text { e que sejam importantes nas diversas dis- } \\
\text { ciplinas, inclusive na que ministro aulas". } \\
\text { 2- "Sim. Pois a educação ambiental deve } \\
\text { ser abordada em todas as disciplinas, pois } \\
\text { é muito importante". }\end{array}$ \\
\hline
\end{tabular}

Fonte: Dados da pesquisa.

A leitura das categorias nos permitiu perceber que o professor de geografia entende que uma prática interdisciplinar ocorre através da união entre várias disciplinas. Trata-se da ideia geral mais clara da interdisciplinaridade.

Os PCN+ Ensino Médio: Orientações Educacionais complementares aos Parâmetros Curriculares Nacionais (2002), contrapõem essa ideia de que é necessário envolver várias disciplinas, pois segundo ele, a interdisciplinaridade pode ser realizada em uma única disciplina, mostrando que se trata de uma postura pedagógica e política frente ao conhecimento.

Para Mattos (2006), a realização conjunta de atividades em diferentes áreas ou disciplinas, associada à família e à comunidade resulta em um 
trabalho interdisciplinar, propiciando, inclusive, o desenvolvimento da educação ambiental.

Observa-se no quadro 3, não só na concepção do professor de geografia, mas de todos os professores entrevistados na pergunta 2 , o entendimento da existência de uma relação entre a educação ambiental e a interdisciplinaridade.

O PCN, tema transversal meio ambiente (1998, p.194) propõe: "É interessante, ainda que se destaque o ambiente como parte do contexto geral as relações ser humano/ser humano e ser humano/ natureza, em todas as áreas de ensino na abordagem dos diferentes conteúdos".

No entanto, para Dutra (2005), as experiências escolares em educação ambiental são esporádicas: dias especiais, comemorativos nos quais os alunos desenvolvem gincanas ou competições de arrecadação de resíduos, e passando o período, a escola volta a sua rotina normal. Nestas atividades os conhecimentos são fragmentados e não se busca um entendimento mais complexo, com o desenvolvimento de valores, contextualizando o meio ambiente como parte do aluno

As respostas dos professores de biologia e espanhol permitiu categorizá-las em 'tema ou assunto a ser estudado, papel central, como unificador das disciplinas'. Realmente o tema ou assunto a ser estudado deve ser relevante para as disciplinas que estão trabalhando de maneira interdisciplinar, indo além delas.

$\mathrm{O}$ enfoque interdisciplinar preconiza a ação das diversas disciplinas em torno de temas específicos. Assim, torna-se imperativa a cooperação/ interação entre todas as disciplinas. Ultimamente, tem sido, muito grande as contribuições por parte das artes, dado o seu grande potencial de trabalhar com sensibilização, elemento essencial para comunicar-se efetivamente. Antes, a EA ficava restrita à área de Ciências ou Biologia, o que foi um erro. Precisamos praticar a EA de modo que ela possa oferecer uma perspectiva global da realidade e não uma perspectiva científica e biológica apenas. São importantes os aspectos sociais, históricos, geográficos, matemáticos, de línguas, da expressão corporal, da filosofia, etc." (DIAS, 1994, p.117).
Assim, o professor de biologia e espanhol possuem uma concepção de que a interdisciplinaridade não está restrita a uma única disciplina, principalmente na área de Ciências da Natureza, como é o caso da biologia. Através de temas relacionados a temática ambiental as várias disciplinas podem abordar a sua visão engrandecendo a discussão.

A categoria 'devem ter pontos em comum ou um objetivo comum' foi encontrada nas respostas dos professores de matemática e artes. Ela nos traz uma visão mais restrita de um trabalho interdisciplinar, pois entendemos que somente as disciplinas afins ao meio ambiente deveriam trabalhar com a educação ambiental, o que contradiz as próprias respostas desses professores ao dizerem que a educação ambiental deve ser trabalhada por todas as disciplinas.

Segundo Miranda (et al., 2010), os alunos irão construir uma visão da globalidade das questões ambientais quando cada profissional de ensino, mesmo especialista em determinada área do conhecimento, seja um dos agentes da interdisciplinaridade que o tema exige. Quando os professores de todas as disciplinas discutem e expõem suas dificuldades e pontos em comum para desenvolver determinado trabalho torna-o mais rico, superando a visão fragmentada do conhecimento pelos professores especialistas.

Cada professor deverá contemplar a temática ambiental dentro da especificidade de sua área, contribuindo para que cada aluno tenha uma visão mais integrada do ambiente.

O termo 'planejamento das práticas pedagógicas' aparece nas respostas dos professores de português, educação física e inglês. $\mathrm{O}$ ato de planejar faz parte da natureza humana, e na prática pedagógica não é diferente.

O planejamento é,

"Um processo de previsão de necessidades e racionalização de emprego dos meios materiais e dos recursos humanos disponíveis, a fim de alcançar objetivos concretos, em prazos determinados e etapas definidas, a partir do conhecimento e avaliação cientifica da situação original" (MARTINEZ e LAHONE, 
1977, p.11).

De fato, uma prática interdisciplinar requer um planejamento de todas as ações didáticas para que as diferentes disciplinas posam dar a sua contribuição.

A última categoria apresentada no quadro 3 foi a concepção da interdisciplinaridade como um 'contato superficial e informal entre as disciplinas', percebido nas respostas dos professores de física e ciências. Tal categoria reflete na falta de conceituação teórica sobre o tema e demonstra carência desses professores por reflexões mais aprofundadas sobre a interdisciplinaridade.

Muitas das práticas ditas pelos professores como interdisciplinares, são na verdade, multidisciplinares, ou seja, conteúdos escolares mais ou menos afins que tratam de uma mesma temática, cada qual no âmbito do seu domínio curricular - uma justaposição dos conteúdos. O que, com certeza, é um avanço diante da compartimentalização do saber, mas não suficiente para ser denominado de interdisciplinaridade (MARINHO, 2004).

Trabalhar de forma interdisciplinar, segundo D’Ambrosio (2001) não significa negar as especialidades e os objetivos de cada área, significa promover uma interação ativa entre as disciplinas, um intercâmbio de conhecimento, respeitando o território de cada campo do conhecimento e enriquecendo a abordagem do tema.

A interdisciplinaridade, ainda é, portanto, realizada de forma discreta na escola objeto de estudo. Esta conclusão pôde ser evidenciada a partir das concepções apresentadas pelos professores durante a pesquisa.

\section{Considerações finais}

Partindo do nosso interesse enquanto docentes e praticantes da educação ambiental, buscamos analisar as concepções de educação ambiental e interdisciplinaridade dos professores do Colégio Estadual Benedito Barreto do Nascimento.

A análise dos questionários nos levou a concluir que as concepções dos professores sobre a educação ambiental são bastante heterogêneas, podendo encontrar elementos das sete categorias identificadas por Suavé (2005) e modificadas por Nero e Frenedozo (2009). Isto é, de certa forma, interessante, pois esta pluralidade nos revela que as experiências cotidianas de cada um, aliadas à formação da sua área influencia na forma de conceber o mundo e compreender os problemas ambientais.

A maioria dos professores relataram que não cursaram disciplinas relacionadas com a educação ambiental em sua formação inicial, mostrando que existe uma deficiência em relação a formação dos professores nas universidades.

Também ficou constatado que a maioria dos professores já realizaram trabalhos de educação ambiental, mostrando que mesmo com uma formação inicial deficiente, existe uma preocupação com a temática.

Já em relação a interdisciplinaridade, percebemos que a maioria dos professores compreendem alguns aspectos da interdisciplinaridade, mas ainda não têm construído um conceito sólido sobre o tema, revelando assim, alguma falha em sua formação superior e também na continuidade de sua formação.

Faz-se necessário realizar novas investigações, para avaliar a aplicabilidade dos conhecimentos de educação ambiental e interdisciplinaridade em sala de aula e a influência das práticas pedagógicas dos professores para a formação do cidadão.

\section{Referências bibliográficas}

BARDIN, L. Análise de Conteúdo. Lisboa: Edições 70, 1977. Tradução de: L. de A. Rego \& A. Pinheiro.

BRASIL. Ministério da Educação e Cultura. Secretaria de Educação Fundamental. Parâmetros Curriculares Nacionais: terceiro e quarto ciclos do Ensino Fundamental: tema transversal meio ambiente. Brasília: MEC/SEF, 1998.

. Ministério da Educação e Cultura. Parâmetros Curriculares Nacionais: Ensino médio. Brasília: MEC/SEF, 1999.

- Ministério da Educação. Secretaria da Educação Média e Tecnológica. Parâmetros Curriculares Nacionais $+(\mathbf{P C N}+)-$ Ciências 
da Natureza e suas Tecnologias. Brasília: MEC, 2002.

Ministério da Educação. Sinopse do Professor da Educação Básica. Brasília: MEC/ INEP, 2010.

CASTÔR, T. R.; CASAGRANDE, L. C.; TRAZZI, P. S. da S. Concepções de Educação Ambiental de um Grupo de Professores do Ensino Médio de uma Escola Estadual do Espírito Santo. Revista da SBEnBio, n. 7, out. 2014.

CERVO, A. L.; BERVIAN, P. A; DA SILVA, R. Metodologia Científica. 6. ed. São Paulo: Pearson Prentice Hall, 2007.

CHIZZOTTI, A. Pesquisa em Ciências Humanas e Sociais. São Paulo: Cortez, 1991.

D'AMBROSIO, U. Etnomatemática: elo entre as tradições e a modernidade. Belo Horizonte: Autêntica, 2001.

DIAS, G. F. Atividades Interdisciplinares de Educação Ambiental. São Paulo: Global/Gaia, 1994.

DUTRA, M. R. O. Professores e Educação Ambiental: uma relação produtiva. Dissertação (Mestrado). Universidade Federal de Pelotas, Programa de Pós Graduação em Educação. Pelotas, 2005.

GUIMARÃES, M. Educação Ambiental: no consenso um embate? Campinas, São Paulo: Papirus, 2000.

JAPIASSÚ, H. Interdisciplinaridade e Patologia do Saber. Rio de Janeiro: Imago, 1976.

MARINHO, A. M. S. A Educação Ambiental e o Desafio da Interdisciplinaridade. Dissertação (Mestrado). Pontifícia Universidade Católica de Minas Gerais, Programa de Pós-Graduação em Educação. Belo Horizonte, 2004.

MARTINEZ, M.J.; LAHONE, C.O. Planejamento Escolar. São Paulo: Saraiva, 1977.
MATTOS, S. A Educação Ambiental na Escola: Teoria x prática sob o ponto de vista interdisciplinar. II Fórum Ambiental da Alta Paulista. 25 a 28 de outubro de 2006. Disponível em: $<$ wwwamigosdanatureza.org.br $>$. Acesso em: 20 maio 2009.

MIRANDA, F. H. da F.; MIRANDA, J. A.; RAVAGLIA, R. Abordagem Interdisciplinar em Educação Ambiental. Revista Práxis, ano 11, n. 4, ago. 2011.

NERO, F. G. D.; FRENEDOZO, R. DE C. Concepções dos Discentes dos Cursos de Licenciatura Sobre Educação Ambiental, sua Responsabilidade Social e o Papel Formativo da Universidade. UCS, Florianópolis, 2009.

OLIVEIRA, S. L. Tratado de Metodologia Científica. São Paulo: Pioneira, 1997.

PATTON, M. G. Qualitative Research and Evaluation Methods. 3. ed. Thousand Oaks, CA: Sage, 2002.

REIGOTA, M. Meio Ambiente e Representação Social. Questões de Nossa Época. São Paulo: Cortez, 1995.

SORRENTINO, M. Educação Ambiental e Universidade: um estudo de caso. Tese (Doutorado em Educação). Universidade de São Paulo. São Paulo, 1995.

SOUZA, J. C. de S. L. de. Educação Ambiental e Interdisciplinaridade: Um olhar sobre as concepções dos docentes e gestores. Dissertação (Mestrado em Ciências da Educação). Universidade Lusófona de Humanidades e Tecnologias. Lisboa - Portugal, 2012.

SUAVÉ, L. Uma cartografia das correntes em educação ambiental. In: SATO M. e CARVALHO, I. C. M. (orgs.). Educação Ambiental: Pesquisas e Desafios. p. 18-44. Porto Alegre: Artmed, 2005..

ZAMONER, M. et al. Concepções dos docentes do ensino fundamental e médio sobre educa- 
ção ambiental e prática interdisciplinar. Anais do IV EDUCERE, 2004.

\section{Sobre os autores}

Pedro Ernesto Oliveira da Cruz: Graduado em Licenciatura em Química pela Universidade Federal de Sergipe (2009) e Mestrado em Química de Produtos Naturais pela mesma Instituição (2011). Atualmente é professor da Secretaria de Estado de Educação de Sergipe. E-mail: pedroernesto99@hotmail.com.

Rodrigo Bozi Ferrete: Professor efetivo do Instituto Federal de Sergipe (IFS). Doutor em Educação pela Universidade Federal de Sergipe, Mestre em Educação pela Universidade Federal do Rio Grande do Norte e graduado em Licenciatura em Matemática pela Universidade do Estado do Pará. E-mail: rbferrete@ gmail.com. 